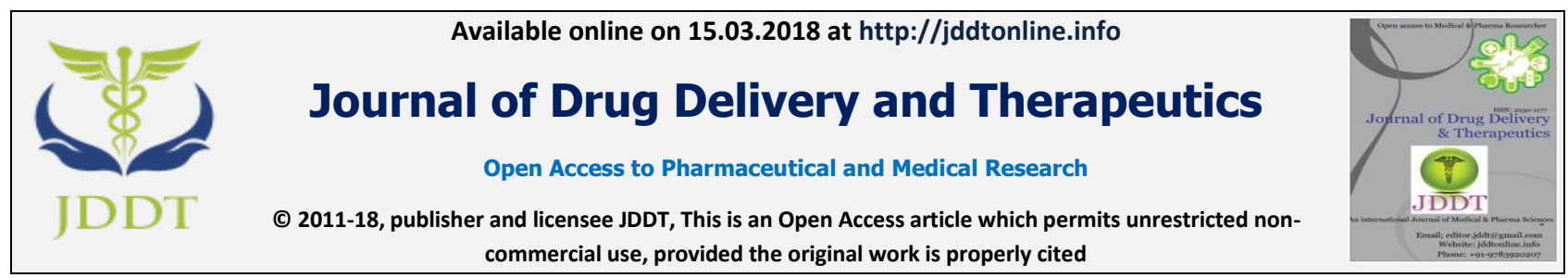

Open $\odot$ Access

Research Article

\title{
STUDIES ON MICROCRYSTALLINE CELLULOSE OBTAINED FROM SACCHARUM OFFICINARUM 2: FLOW AND COMPACTION PROPERTIES
}

\author{
Nkemakolam Nwachukwu*, Kenneth Chinedu Ugoeze \\ Department of Pharmaceutics and Pharmaceutical Technology, University of Port Harcourt, Port Harcourt, Rivers State, Nigeria
}

\section{ABSTRACT}

Microcrystalline cellulose (MCC) derived from Saccharum officinarum stem was evaluated for its powder flow and compaction properties in order to assess its suitability as a potential direct compression excipient in tablet formulations. Alpha $(\alpha)$ cellulose obtained from different sodium hydroxide and bleaching treatments of dried shred S. officinarum stem pulp was hydrolyzed with 2.5 $\mathrm{N}$ hydrochloric acid $(2.5 \mathrm{~N} \mathrm{HCl})$ to obtain MCC which was coded MCC-Sacc. This was compared with a commercial brand, Avicel PH 102. The results of powder flow parameters such as bulk, tapped and particle densities $(0.41 \pm 0.01,0.54 \pm 0.01$ and $1.52 \pm 0.10$ $\mathrm{g} / \mathrm{mL}$ respectively), porosity (78.69 $\pm 0.20 \%)$, Carr's index $(31.47 \pm 0.75 \%)$, Hausner's quotient (1.47) and angle of repose (31.00 $\left.\pm 1.00^{\circ}\right)$ indicate poor flowability. Kawakita model assessment of powder showed good densification and cohesiveness. Compacts of MCC-Sacc showed good uniformity of weight, friability, disintegration and mechanical strength. The Heckel model showed good plasticity and slippage of the material. Values obtained were comparable to Avicel PH 102 in terms of compressibility and mechanical strength, hence $M C C$-Sacc has a good potential for use as a pharmaceutical excipient in the direct compression method of tablet formulation.

Keywords: Microcrystalline cellulose, Saccharum officinarum, Avicel PH 102, powder, compaction.

Article Info: Received 09 Jan, 2018; Review Completed 17 Feb, 2018; Accepted 17 Feb, 2018; Available online 15 March, 2018

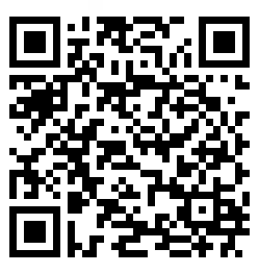

Cite this article as:

Nwachukwu N, Ugoeze KC, Studies on microcrystalline cellulose obtained from Saccharum officinarum 2: flow and compaction properties, Journal of Drug Delivery and Therapeutics. 2018; 8(2):54-59

DOI: http://dx.doi.org/10.22270/jddt.v8i2.1666

*Address for Correspondence

Nkemakolam Nwachukwu, Department of Pharmaceutics and Pharmaceutical Technology, University of Port Harcourt, Port Harcourt, Rivers State, Nigeria

\section{INTRODUCTION}

Microcrystalline cellulose is a purified partially depolymerized nonfibrous form of cellulose derived mostly from wooden plants and cotton. It is an amorphous, odourless, tasteless, crystalline powder composed of porous particles which are most times whitish in colour. It has been widely used in the cosmetics, food and pharmaceutical industries as a suspension stabilizer and reinforcing agent for final products such as medical tablets ${ }^{\mathbf{1}}$. In recent times, awareness of its benefits especially in the pharmaceutical sector as a directly compressible excipient has boosted its use in the direct compression of tablets. It is regarded as probably the best dry filler- binder currently available ${ }^{2}$ Microcrystalline cellulose also exhibits a high dilution potential which makes it suitable for the formulation of low dose and potent drugs. Besides wood pulp and cotton linters, literature search shows that MCC has been prepared from other sources such as Indian bamboo ${ }^{3}$, groundnut husk ${ }^{4}$, cotton stalk pulps ${ }^{5}$, hosiery waste ${ }^{6}$, corncobs $^{7}$, Sorghum caudatum $^{8}$, water hyacinth ${ }^{9}$ and Saccharum officinarum 10. These different sources as well as processing conditions usually affect the properties of the cellulose in terms of surface area, porosity, crystallinity, molecular weight, moisture content and shape. These differences would obviously affect the powder and compaction behavior of the MCC. Saccharum 
officinarum commonly called sugar cane is a large, tall plant of the perennial grass species (Family: Poaceae) that grows in clumps ${ }^{11}$. Although many species exist, more popular are the species with a green, purple or pinkish coloured stem. Sugar cane stem is stout, jointed, fibrous and rich in sugar. The plant is native to Asia but grows well in warm temperate, sub-tropical and tropical regions of the world ${ }^{11}$. Sugar cane stem pulp or baggase is an agricultural waste that is mostly generated after the sap has been extracted by industrialists who refine it into table sugar or other by-products such as ethanol, rhum, molasses, cachaca, falernum, etc ${ }^{\mathbf{1 0}}$ or by people who consume it as a delicacy because of its sweet sap.

Although MCC produced from S. officinarum has been reported by some other researchers ${ }^{\mathbf{1 2}, \mathbf{1 3}, \mathbf{1 4}}$, there is scanty information on its compaction behavior as a directly compressible excipient without an active pharmaceutical ingredient (API). Thus this work is aimed at evaluating its powder and compaction characteristics as a directly compressible excipient.

\section{MATERIALS AND METHODS}

\section{Materials}

The following materials were used as procured: hydrochloric acid (JHD, China), sodium hydroxide pellets (Qualikems Laboratory Reagents, India), nhexane (Sigma Aldrich, USA), Avicel PH 102 (FMC Biopolymers, USA), sodium hypochlorite $3.5 \% \mathrm{w} / \mathrm{v}$ (Multi Pros Enterprises Ltd., Nigeria). Saccharum officinarum stems were procured from Choba market, Port Harcourt).

\section{Methods}

\section{Derivatization of alpha cellulose}

The experimental procedure employed involved a slight modification of the method of Ohwoavworhua and Adelakun, ${ }^{15}$ and as reported by Nwachukwu and Ugoeze 10. Matured stems of $S$. officinarum were processed by peeling off the stem bark, cutting it into bits of about 2-4 $\mathrm{cm}$, pressing to remove the sap and air drying the sponges for 5 days under ambient conditions until they were sufficiently dry ${ }^{\mathbf{1 0}}$. Initial delignification was done by heating $1.5 \mathrm{~kg}$ mass of the dried sponges in $3.5 \mathrm{~L}$ of $2.0 \% \mathrm{w} / \mathrm{v}$ sodium hydroxide $(\mathrm{NaOH})$ solution for $5 \mathrm{~h}$ at $80{ }^{\circ} \mathrm{C}$ in a stainless steel vessel. The moist mass was drained of excess $\mathrm{NaOH}$, washed with copious amounts of distilled water until neutral to litmus. Excess water was removed by squeezing the resultant mass through a muslin cloth and then heating with $1.5 \mathrm{~L}$ of a $1: 2$ aqueous dilution of sodium hypochlorite solution at 80 ${ }^{\circ} \mathrm{C}$ for $1 \mathrm{~h}$. Further washing with water was done to remove the sodium hypochlorite, followed by squeezing in a muslin cloth to remove excess water. Further delignification was done by heating the bleached mass in $1 \mathrm{~L}$ of $17.5 \% \mathrm{w} / \mathrm{v} \mathrm{NaOH}$ at $80^{\circ} \mathrm{C}$ for $1 \mathrm{~h}$, washing with water until neutral to litmus, squeezing off the water and heating in $1 \mathrm{~L}$ of the 1:2 aqueous dilution of sodium hypochlorite solution at $80{ }^{\circ} \mathrm{C}$ for $1 \mathrm{~h}$. The resultant moist mass - alpha cellulose was washed with distilled water until neutral to litmus. The excess water was squeezed out and the alpha cellulose dried as small lumps in a hot air oven (Memmert ${ }^{\circledR}$, England) at $60{ }^{\circ} \mathrm{C}$ for $2 \mathrm{~h}^{\mathbf{1 0}}$.

\section{Acid hydrolysis of alpha cellulose}

A $50 \mathrm{~g}$ quantity of the alpha cellulose obtained earlier was weighed into a $2 \mathrm{~L}$ glass beaker (Pyrex ${ }^{\circledR}$, England) and hydrolyzed with $1.0 \mathrm{~L}$ of $2.5 \mathrm{~N}$ hydrochloric acid at a temperature of $105 \pm 2{ }^{\circ} \mathrm{C}$ in a paraffin oil bath with constant vigorous stirring using a glass rod for $15 \mathrm{~min}$. The hot acid mixture was poured into cold distilled water, allowed to cool and washed severally with cold distilled water until neutral to litmus. The resultant MCC was strained using a muslin cloth. More MCC was obtained by repetition of this process. The moist MCC was dried in a hot air oven at $60{ }^{\circ} \mathrm{C}$ for $2 \mathrm{~h}$. Milling of the MCC was done with an electric blender (Binatone ${ }^{\circledR}$, Japan) and sized by screening through a $250 \mu \mathrm{m}$ stainless sieve (Retsch ${ }^{\circledR}$, Germany). The derived MCC coded MCC-Sacc was weighed and stored in an airtight glass bottle ${ }^{10}$.

\section{Micromeritic characterization of the MCCs}

\section{Particle density}

The particle density of the MCC powders was determined by the liquid displacement method using nhexane as the immersion fluid. An empty dry $25 \mathrm{~mL}$ pycnometer was weighed empty. It was filled with $n$ hexane, stoppered, and any excess fluid wiped and the pycnometer re-weighed. The pycnometer was emptied and $1 \mathrm{~g}$ mass of the MCC powder placed in it. It was refilled with n-hexane and stoppered. Excess fluid was wiped from its body and the weight also noted. The particle density was calculated as ${ }^{16}$ :

$P d=\frac{\mathrm{W} 2 \times \mathrm{W} 3}{\mathrm{v}(\mathrm{W} 3-\mathrm{W} 4+\mathrm{W} 2+\mathrm{W})}$ 1

Where $P d$ is the particle density, w is the weight of empty pycnometer, $w_{2}$ is the weight of the solvent, $w_{3}$ is the weight of the powder, $\mathrm{w}_{4}$ is the weight of the pycnometer + solvent + powder and $\mathrm{v}$ is the volume of solvent. Triplicate determinations were conducted for each powder sample.

\section{Bulk and tapped density}

The bulk density was determined by pouring $20 \mathrm{~g}$ of each MCC powder into a clean dry graduated $100 \mathrm{~mL}$ glass measuring cylinder kept on a flat surface. The powder was leveled with a spatula and the volume occupied was noted as the bulk volume. The bulk density was calculated as:

Bulk density $\left(D_{b}\right)=M / V_{b} \ldots \ldots \ldots \ldots \ldots \ldots \ldots \ldots \ldots \ldots \ldots \ldots \ldots \ldots$

Where $\mathrm{M}$ is the mass of the powder and $\mathrm{V}_{\mathrm{b}}$ is the bulk volume.

The tapped volume was determined by tapping/dropping the measuring cylinder on a flat padded surface from a distance of $2-3 \mathrm{~cm}$ at $2-3 \mathrm{sec}$ intervals until a constant volume of powder was observed. The tapped density was calculated as:

Tapped density $\left(D_{t}\right)=M / V_{t} \ldots \ldots \ldots \ldots \ldots \ldots \ldots$

Where $\mathrm{V}_{\mathrm{t}}$ is the tapped volume. 


\section{Flow rate and angle of repose}

The dynamic angle of repose was measured using the fixed funnel and free-standing cone method. A $20 \mathrm{~g}$ quantity of each microcrystalline cellulose powder was poured into a clamped stoppered clean glass funnel whose orifice was $5 \mathrm{~cm}$ above a flat surface. The powder was allowed to flow freely under gravity from the funnel unto the platform. The time of flow of the powder, the diameter and height of the powder heap formed were measured and recorded. The flow rate and tangent of the powder heap were calculated as:

$$
\text { F.R. }=\text { M / F.T. ...................... } 4 .
$$

Where F.R. is the flow rate, F.T. is flow time and M is the mass of powder used.

$$
\text { Angle of repose }(\Theta)=\tan ^{-1}(\mathrm{~h} / \mathrm{r}) \ldots \ldots \ldots \ldots . \ldots 5
$$

\section{Hausner's quotient( ratio ) and Carr's index}

The Hausner's quotient and Carr's index for each powder sample were calculated from Equations 6 and 7 17

$$
\begin{aligned}
& \text { Hausners quotient (H.Q.) }=\mathrm{D}_{\mathrm{t}} / \mathrm{D}_{\mathrm{b}} \ldots \ldots \ldots \ldots \ldots 66 \\
& \text { Carr's Index (C.I.) }=\left[1-\left(\mathrm{D}_{\mathrm{b}} / \mathrm{D}_{\mathrm{t}}\right)\right] \text { x } 100 \ldots \ldots \ldots .67
\end{aligned}
$$

\section{Powder porosity}

Powder porosity, $\epsilon$ is obtained when the values of the particle density, $\mathrm{P}_{\mathrm{d}}$ and bulk density, $\mathrm{D}_{\mathrm{b}}$ are fitted into Equation $8^{18}$ :

$$
\epsilon=\left[1-\left(D_{b} / P_{d}\right)\right] \times 100
$$

Where $\epsilon$ is the powder porosity, $D_{b}$ is the bulk density and $\mathrm{P}_{\mathrm{d}}$ is the particle density.

\section{Compactibility and powder cohesion}

The Kawakita Equation can be used to describe the relationship between the pressure applied to a given powder bed in an enclosure and the subsequent reduction in the volume of the powder bed. This would depend on the compactibility and cohesive properties of the powder. This is described by the Kawakita Equation 19.

$$
\mathrm{N} / \mathrm{C}=\mathrm{N} / \mathrm{a}+1 / \mathrm{ab}
$$

Where $\mathrm{N}$ is the number of taps, $\mathrm{C}$ is derived from $\frac{\mathrm{Vo}-\mathrm{V}}{\mathrm{V}}$ where $V_{O}$ is the bulk volume, $V$ is the tapped volume, a is the compatibility of the powder, $1 / \mathrm{a}$ is the slope and $1 / \mathrm{ab}$ the intercept of the plot of N/C against $\mathrm{N}$ and $1 / \mathrm{b}$ the cohesiveness of the powder. A $15 \mathrm{~g}$ sample each of MCC-Sacc and Avicel PH 102 was poured into a $50 \mathrm{~mL}$ clean, dry graduated glass measuring cylinder and the bulk volume and volume reduction after an incremental number of taps until there was no further reduction in volume was noted. The compactibility and cohesiveness were determined from the Kawakita plots.

\section{Powder compaction}

Compaction of MCC-Sacc and Avicel PH 102 was done at compression pressures ranging from 4.9 to $14.71 \mathrm{MPa}$ (MegaPascal) using a $10 \mathrm{~mm}$ flat faced set of punches fitted to a single punch hydraulic tablet press (Model C, Carver Inc., Wisconsin, USA). Compacts of $300 \mathrm{mg}$ target tablet weight were produced by manually feeding the MCC powders into the tablet press and compressing at the set compression pressure.

\section{Evaluation of compacts}

A $24 \mathrm{~h}$ post-compression relaxation time to allow the compacts recover from the compression stress was allowed before the compacts were evaluated for uniformity of weight, hardness, thickness, disintegration time, friability and tensile strength.

\section{Uniformity of weight}

From each batch of MCC-Sacc and Avicel PH 102, twenty compacts were randomly selected and weighed individually. The mean, standard deviation, and coefficient of variance were calculated. Acceptance or rejection was based on the British Pharmacopoeia acceptance limits for uncoated tablets weighing above $250 \mathrm{mg}^{20}$.

\section{Hardness}

Ten tablets were randomly selected from the different batches of MCC-Sacc and Avicel PH 102 compacts and their hardness determined using an Erweka TBH 200 hardness tester $\left(\right.$ Erweka $^{\circledR}$, Germany). The mean and standard deviations of values obtained were determined.

\section{Thickness and diameter}

Ten compacts were randomly selected from each batch of the MCC compacts and their thickness and diameter determined using a micrometer screw gauge. The mean and standard deviations were calculated.

\section{Disintegration time}

An Erweka ZT-300 twin basket disintegration tester (Erweka ${ }^{\circledR}$, Germany) was used for this test. Six tablets randomly selected from each batch of MCC-Sacc and Avicel PH 102 were individually put inside each of the six holes of the basket assembly and held with a glass disc. A $500 \mathrm{~mL}$ volume of $0.1 \mathrm{~N} \mathrm{HCl}$ heated up to $37 \pm$ $1^{\circ} \mathrm{C}$ was used as disintegration medium and the time taken for each compact to break up and completely pass through the mesh was determined. Replicate readings were done.

\section{Friability}

Ten tablets randomly selected from each batch of the compacts were de-dusted, collectively weighed and put in one of the drums of an Erweka model TAR 200 (Erweka ${ }^{\circledR}$, Germany) twin drum electronic friabilator programmed to revolve at 25 revolutions per minute (rpm) for $4 \mathrm{~min}$. At the end of the exercise the tablets were collected and re de-dusted and any broken tablets rejected. The tablets were reweighed and the percentage friability or abrasion resistance calculated from Equation $11^{21}$. Replicate determinations were done.

$$
\% \text { Friability }=100\left(1-\mathrm{W} / \mathrm{W}_{\mathrm{o}}\right)
$$

Where $\mathrm{W}_{\mathrm{o}}$ is the initial weight and $\mathrm{W}$ is the final weight of the compacts or tablets. 


\section{Tensile strength}

The tensile strength of the compacts was determined using Equation $12^{22}$.

Tensile strength $\left(\mathrm{T}_{\mathrm{S}}\right)=2 \mathrm{P} / \pi \mathrm{dt}$

Where $\mathrm{P}$ is the breaking force, $\mathrm{d}$ is the tablet diameter, $\mathrm{t}$ is the tablet thickness.

\section{Heckel analysis}

The Heckel Equation is a model used in the description of the densification behavior of a powder bed from the time a quantified pressure is applied, to the deformation mechanism of the powder in forming a compact. It relates the relative density of a powder bed to the applied compression load during tableting. It is stated as

$$
\operatorname{In}(1 / 1-\mathrm{D})=\mathrm{KP}+\mathrm{A} \ldots \ldots \ldots \ldots \ldots \ldots \ldots \ldots \ldots \ldots \ldots \ldots
$$

Where $\mathrm{D}$ is the relative density of a powder compact at pressure $\mathrm{P}, \mathrm{K}$ is the slope of the straight line portion of the plot ( a measure of the plasticity of the compressed material) and is the reciprocal of the mean yield pressure $\mathrm{Py}$, of the material. A is the $\mathrm{Y}$-axis intercept of the plot. The relative density $\mathrm{D}_{\mathrm{A}}$ can be derived from Equation 14 24 .

$$
\mathrm{D}_{\mathrm{A}}=1-\mathrm{e}^{-\mathrm{A}}
$$

The powders relative density at the point when the applied pressure is zero is denoted as $D_{O}$ and is descriptive of the initial rearrangement phase of densification as a result of die filling. The relative density $D_{B}$, is descriptive of the rearrangement phase of the powder at low pressures and is derived from the difference between $D_{A}$ and $D_{O}$ as shown in Equation 15:

$$
\mathrm{D}_{\mathrm{B}}=\mathrm{D}_{\mathrm{A}}-\mathrm{D}_{\mathrm{O}}
$$

\section{Statistical analysis}

Data obtained were statistically evaluated using ANOVA and the student's t-test (IBM SPSS 21) and were considered significant at $\mathrm{p}<0.05$.

\section{RESULTS AND DISCUSSION}

\section{Micromeritic properties of the powders}

Results of the flow indices are shown in Table 1. Results obtained for MCC-Sacc in terms of bulk and tapped density $(0.41 \pm 0.01$ and $0.59 \pm 0.01)$ respectively, angle of repose $(31.00 \pm 1.00)$, Hausner's quotient (1.47 \pm $0.01)$, Carr's compressibility index $(31.47 \pm 0.75)$, point to the fact that MCC-Sacc does not have a good flow ${ }^{25}$.

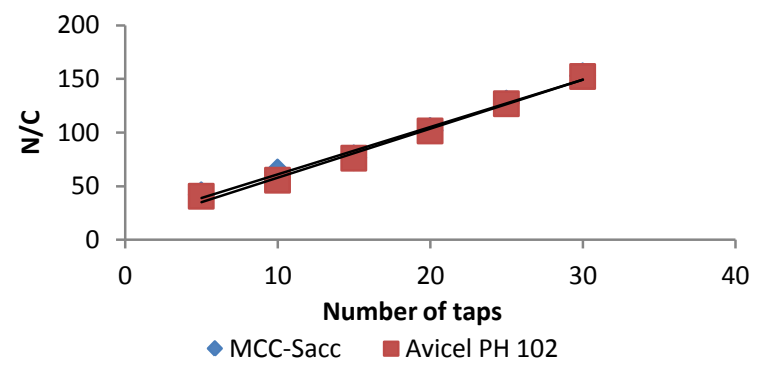

Figure 1: Kawakita plots of MCC-Sacc and Avicel PH 102

Table 1: Micromeritic properties of $M C C$-Sacc and Avicel PH 102 compacts

\begin{tabular}{lll}
\hline Sample/Parameter & MCC-Sacc & Avicel PH 102 \\
\hline & & \\
Bulk density $(\mathrm{g} / \mathrm{mL})$ & $0.41 \pm 0.01$ & $0.31 \pm 0.04$ \\
Tapped density $(\mathrm{g} / \mathrm{mL})$ & $0.54 \pm 0.01$ & $0.38 \pm 0.02$ \\
Angle of repose $\left({ }^{\circ}\right)$ & $31.00 \pm 1.00$ & $30.52 \pm 2.35$ \\
Flow rate $(\mathrm{g} / \mathrm{s})$ & Poor flow & Poor flow \\
Carr's index $(\%)$ & $31.47 \pm 0.75$ & $18.96 \pm 0.67$ \\
Packing Fraction & $0.76 \pm 0.05$ & $0.81 \pm 0.01$ \\
Hausner's Quotient & $1.47 \pm 0.01$ & $1.23 \pm 0.01$ \\
Porosity $(\%)$ & $78.69 \pm 0.20$ & $80.10 \pm 0.27$ \\
Particle density $(\mathrm{g} / \mathrm{mL})$ & $1.52 \pm 0.10$ & $1.56 \pm 0.07$ \\
Particle size $(\mu \mathrm{m})$ & $7.70 \pm 13.5$ & $5.60 \pm 4.90$ \\
\hline
\end{tabular}

\section{Compactibility and cohesiveness}

The compactibility and cohesiveness of MCC-Sacc and Avicel PH 102 were parameters derived from the Kawakita plot (Fig. 1) and the data obtained therefrom is shown in Table 2. The results show that MCC-Sacc undergoes densification on agitation (tapping) and is cohesive. There was no significant difference $(\mathrm{p}>0.05)$ in the compactibility values of $M C C$-Sacc and Avicel PH 102. The compactibility or compressibility of both MCC-Sacc and Avicel PH 102 were very similar as shown in Table 2. However, Avicel PH 102 was less cohesive (0.03) than MCC-Sacc (0.08) and therefore is expected to have a better flow than MCC-Sacc.

Table 2: Compactibility and cohesiveness

\begin{tabular}{lllllll}
\hline Sample/Parameter & $\mathrm{a}$ & $\mathrm{b}$ & $1 / \mathrm{a}$ & $1 / \mathrm{b}$ & $1 / \mathrm{ab}$ & $\mathrm{R}^{2}$ \\
\hline MCC-Sacc & 0.23 & 0.08 & 4.42 & 12.31 & 16.73 & 0.99 \\
Avicel PH 102 & 0.22 & 0.03 & 3.39 & 7.87 & 12.43 & 0.99 \\
\hline
\end{tabular}




\section{Compact properties}

Tables 3 shows some compact properties: uniformity of weight, disintegration time and hardness of MCC-Sacc and Avicel PH 102. Compacts of both materials exhibited a weight that conformed to BP set limits for uncoated tablets as none of the batches at the different compression pressures employed had a coefficient of variance of more than $5 \%$. The disintegration time of all the compacts ranged from $1.54 \pm 0.25$ to $14.82 \pm 0.70$ min and can be adjudged to have complied with the BP set limits for the disintegration time of uncoated tablets which is given as $\leq 15 \mathrm{~min}^{20}$. Avicel PH 102 compacts had disintegration time values that were significantly higher $(\mathrm{p}<0.05)$ than those of MCC-Sacc at all compression pressures. The disintegration mechanism of the compacts is postulated to be as a result of penetration of water into the hydrophilic compact matrix by capillary action of the pores and subsequent disruption of the hydrogen bonds ${ }^{26}$. The rate of water penetration into the matrix may have been affected by the hardness of the compact. The hardness values ranged from $4.27 \pm$ 0.86 to $6.96 \pm 1.54 \mathrm{~kg} / \mathrm{F}$ for $M C C$-Sacc (Table 3). These values conformed to hardness test specifications for uncoated tablets as given by the $\mathrm{BP}{ }^{20}$, whereas Avicel PH 102 compacts had values that ranged from $3.47 \pm$ 1.47 to $28.09 \pm 1.52 \mathrm{~kg} / \mathrm{F}$. The Avicel PH 102 compacts fell short of the hardness test set limits by the BP for uncoated tablets except for compacts compressed at $4.90 \mathrm{MPa}$. All the Avicel PH 102 compacts compressed at $\geq 7.35 \mathrm{MPa}$ were significantly $(\mathrm{p}<0.05)$ harder than MCC-Sacc. The tensile strengths also confirm the mechanical strength of the compacts of both materials. However, Avicel PH 102 displayed superior tensile strength than MCC-Sacc at similar compression pressures except at 4.90 MPa. Microcrystalline cellulose compacts are generally strong because the plastically deformed compacts have in their structure groups of hydrogen bonds which are attached to adjacent cellulose particles $^{26}$.The compacts of both MCCs were $\leq 1 \%$ friable (Fig. 3) and are adjudged to have met with the set specifications for uncoated tablets ${ }^{20}$. Thus a good mechanical strength and friability ensure that such compacts can withstand handling and transportation stresses that they may be exposed to and a similar behavior would be expected when they are used in drug formulations as tablets.

The Heckel analysis parameters (Table 4) which were derived from the Heckel plot (Fig. 4) show that both materials undergo plasticity and slippage. The $\mathrm{K}$ value of Avicel PH 102 was lower than that of MCC-Sacc implying that $M C C$-Sacc undergoes plasticity faster than Avicel $\mathrm{PH}$ 102. The $\mathrm{D}_{\mathrm{O}}$ values were the same implying that initial packing and rearrangement in the die were similar for both materials. The $D_{B}$ which describes the rearrangement phase at low compression pressures show that $M C C$-Sacc at low pressures is rearranged faster than Avicel PH 102.

Table 3: Physical properties of MCC-Sacc and Avicel PH 102 compacts.

\begin{tabular}{|c|c|c|c|c|c|c|}
\hline \multirow{2}{*}{$\begin{array}{l}\text { Compression } \\
\text { pressure }(\mathrm{MPa})\end{array}$} & \multicolumn{2}{|c|}{ Uniformity of weight (mg) } & \multicolumn{2}{|c|}{ Disintegration (min) } & \multicolumn{2}{|c|}{ Hardness $(\mathrm{kg} / \mathrm{F})$} \\
\hline & MCC-Sacc $(\%)^{*}$ & $\begin{array}{l}\text { Avicel PH } 102 \\
(\%)^{*}\end{array}$ & MCC-Sacc & $\begin{array}{l}\text { Avicel PH } \\
102(\%)\end{array}$ & MCC-Sacc & $\begin{array}{l}\text { Avicel PH } \\
102(\%)\end{array}$ \\
\hline 4.90 & $315.20 \pm 0.50$ & $297.45 \pm 1.41$ & $1.54 \pm 0.25$ & $4.02 \pm 0.86$ & $4.27 \pm 0.86$ & $3.47 \pm 1.47$ \\
\hline 7.35 & $313.03 \pm 1.00$ & $299.50 \pm 1.42$ & $2.33 \pm 0.10$ & $5.42 \pm 0.94$ & $5.27 \pm 1.73$ & $19.24 \pm 4.51$ \\
\hline 9.81 & $315.45 \pm 0.20$ & $297.50 \pm 0.21$ & $2.43 \pm 0.04$ & $10.22 \pm 0.86$ & $6.50 \pm 1.62$ & $25.14 \pm 2.36$ \\
\hline 12.26 & $315.30 \pm 0.04$ & $296.05 \pm 1.97$ & $3.05 \pm 0.62$ & $12.61 \pm 0.33$ & $6.96 \pm 1.54$ & $28.07 \pm 1.53$ \\
\hline 14.71 & $314.50 \pm 0.10$ & $298.00 \pm 1.36$ & $3.02 \pm 0.50$ & $14.82 \pm 0.70$ & $6.28 \pm 0.95$ & $28.09 \pm 1.52$ \\
\hline
\end{tabular}

Table 4: Heckel parameters of MCC-Sacc and Avicel PH 102

\begin{tabular}{llllllll}
\hline Sample/Parameter & $\mathrm{K}$ & $\mathrm{Py}\left(\mathrm{kNm}^{-2}\right)$ & $\mathrm{D}_{\mathrm{O}}$ & $\mathrm{D}_{\mathrm{A}}$ & $\mathrm{D}_{\mathrm{B}}$ & $\mathrm{A}$ & $\mathrm{R}^{2}$ \\
\hline MCC-Sacc & 3.21 & 0.31 & 0.23 & 0.50 & 0.51 & -0.68 & 0.99 \\
Avicel PH 102 & 5.25 & 0.19 & 0.23 & 0.74 & 0.27 & -1.33 & 0.98 \\
\hline
\end{tabular}

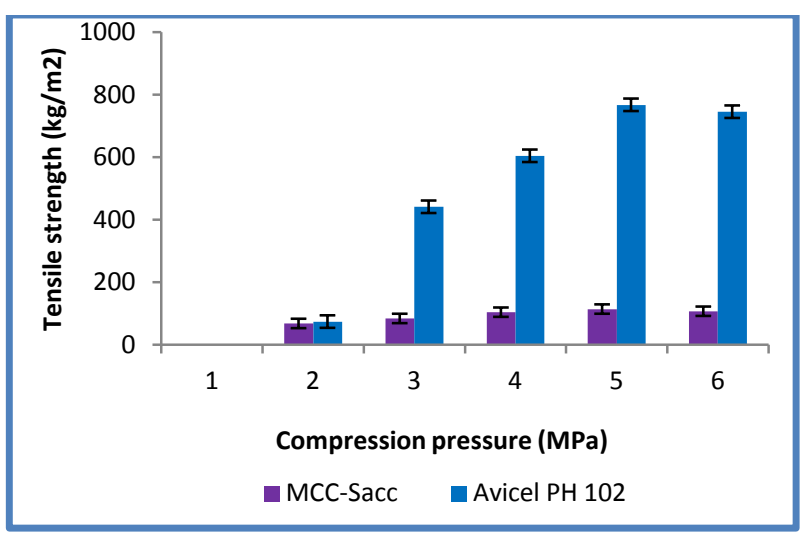

Figure 2: Tensile strength of MCC-Sacc and Avicel PH 102 at different compression pressures

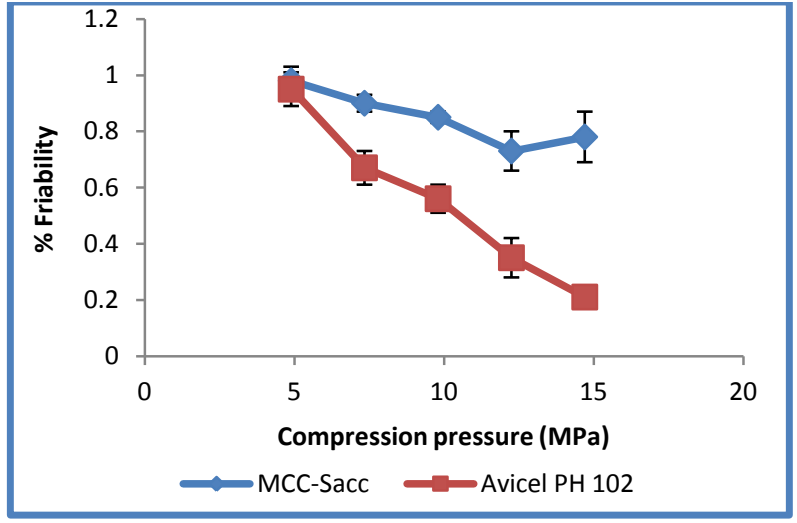

Figure 3: Friability of MCC-Sacc and Avicel PH 102 


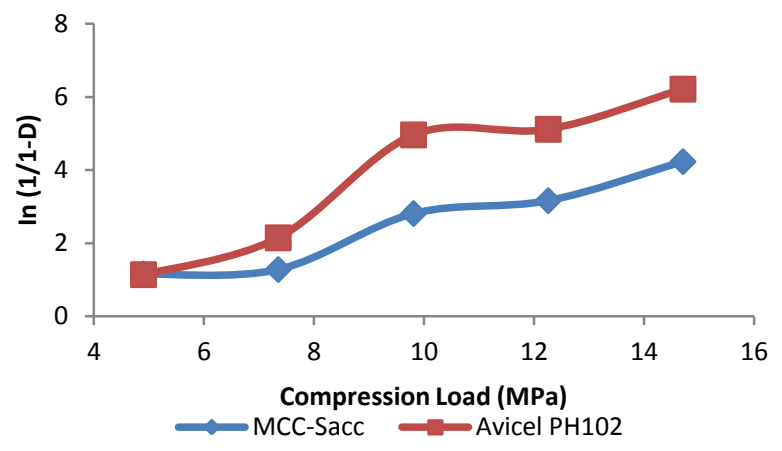

Figure 4: Heckel plot of MCC-Sacc and Avicel PH 102

\section{CONCLUSION}

The results of some micromeritic evaluation tests conducted showed that MCC-Sacc flows poorly and densifies on tapping. The flow and densification indices were comparable to the commercial powder, Avicel PH 102 which was used as comparing standard, although Avicel PH 102 flowed better than MCC-Sacc. The

\section{REFERENCES}

1. Laka M, Chernyavskaya S, Obtaining microcrystalline cellulose from softwood and hardwood pulp, Bioresources, 2007; 2(3):583-589.

2. Battista OA, Microcrystalline cellulose. In Bilkales NM, Segal L. (eds), Cellulose and Cellulose Derivatives. John Wiley and Sons, New York, USA, 1971, pp. 1265-1276.

3. Umeh ONC, Nworah AC, Ofoefule SI, Physicochemical properties of Microcrystalline cellulose derived from Indian bamboo (Bambusa vulgaris), Int. J. Pharm. Sci. Rev. Res., 2014; 29 (2):5-9.

4. Ohwoavworhua FO, Adekunle TA, Okahmafe OA, Processing pharmaceutical grade microcrystalline cellulose from groundnut husk: Extraction methods and characterization, Int. J.Green Pharm.,2009; 3(2):97-104.

5. El-Sakhawy M, Hassan ML, Physical and Mechanical Properties of Microcrystalline cellulose from agricultural residues, Carbohydrate Polymers, 2005; 67:1-10.

6. Anand SM, Chawla JS, (1981), Microcrystalline cellulose from hosiery waste, Research and Industry, 1981; 26:227-235.

7. Azubuike CP, Esiaba J, Investigation into some PhysicoTechnical and Tabletting Properties of low crystallinity powdered cellulose prepared from corn residues, Journal of Pharmaceutical Research and Opinion, 2012; 2(8):94-98.

8. Ohwoavworhua FO, Adelakun TA, A nonwood fiber production of microcrystalline cellulose from Sorghum caudatum: characterization and tableting properties, Indian J. Pharm. Sci. 2010; 72(3):295-301.

9. Suryadi H, Sutriyo, Sari HR, Rosikhoh D, Preparation of Microcrystalline cellulose from water hyacinth powder by enzymatic hydrolysis using cellulose of local isolate, J. Young Pharm., 2017, 9(1): 19-23.

10. Nwachukwu N and Ugoeze KC. Studies on Microcrystalline cellulose obtained from Saccharum officinarum 1: Processing and Physicochemical Properties, European Journal of Biomedical and Pharmaceutical Sciences, 2018; 5(2):42-48.

11. Hai HD, Saccharum officinarum, downloaded on 15/2/2018 @ world wide vegetables.ebly.com

12. Ohwoavworhua FO, Ogah E., Kunle OO, Preliminary investigation of physicochemical and functional properties of alpha cellulose obtained from waste paper: A potential pharmaceutical excipient, Journal of Raw Material Research, $2005 ; 2: 84-93$.

13. Adedokun MO, Nkori RE, Preliminary investigation of Mechanical Properties of Paracetamol Tablets Formulated With Microcrystalline Cellulose Binder Derived From Saccharum compacts obtained from the direct compression of the powders of both MCCs complied with BP set limits for uncoated tablets.The compacts exhibited good mechanical properties that would ensure that they do not lose their physical integrity during packaging, transportation and storage. Both disintegration time and friability of the compacts generally met with BP set limits. The Kawakita model results show the MCC powders to be compactible and cohesive while the Heckel model showed that both MCC-Sacc and Avicel PH 102 undergoes slippage and plastic deformation. The results obtained from the different evaluation tests show that MCC-Sacc compares well with Avicel PH 102 in terms of flowability, compressibility and mechanical strength of the compacts which would enhance the formation of good tablets. This confirms the potentiality of microcrystalline cellulose derived from Saccharum officinarum as a dry binder for use in the formulation of tablets through the direct compression method.

\section{Conflict of interest: Nil}

officinarum, L. Asian Journal of Biomedical and Pharmaceutical Sciences, 2014; 4(38):17-22.

14. Onyishi IV, Chime SA, Okoroji CA, Physicochemical Properties of Microcrystalline Cellulose from Saccharum officinarum: Comparative Evaluation with Avicel PH 101, American Journal of Pharm. Tech. Research, 2013; 3(5):414-426.

15. Ohwoavworhua FO, Adelakun TA, Some Physical Characteristics of microcrystalline cellulose obtained from raw cotton of Cochlospermum planchonii, Trop. J. Pharm. Res. 2005: 4(2):501-507.

16. Ugoeze KC, Nwachukwu N, Nwodo CC, Excipient Functionality of a Novel Hydrophilic Biopolymer derived from Ipomoea batatas Tubers. Indo American Journal of Pharmaceutical Research, 2017; 7(7):360-368

17. Sihtola H, Kyrkxund B, Laamansn L, Palbmius I, Comparison and conversion of viscosity and DP values determined by different methods. Pan. Puu. 1963; 45:225-232.

18. Neuman BS, The Flow Properties of Powders, Advances in Pharmaceutical Sciences, Academic Press, London, 1967, pp. 181-188.

19. Kawakita K, Ludde KH, Some considerations on powder compression equations, Powder Technol., 1970/1971; 4:61.

20. British Pharmacopoeia. Vol.II, Her Majesty Stationary Office, University Press, Cambridge, 2012; A326:327.

21. Ofoefule SI, Textbook of Pharmaceutical Technology and Industrial Pharmacy, Samakin Nig. Enterprises, Lagos, 2006, pp. $24-68$.

22. United States Pharmacopoeia, USP 32, Vol. 2, The United States Pharmacopoeial Convention, Rockville M.D., 2009, pp.2113-2116, 3017.

23. Duberg M, Nystrom C, Studies on direct compression of tablets VI. Evaluation of methods for the estimation of particle fragmentation during compaction. Acta Pharm. Suec., 1982; 19:421-436.

24. Humbert-Droz P, Gurney R, Mordier D, Doelker E, Densification behavior of drugs presenting availability problems, Int. J. Pharm. Tech, Prod. Mfr, 1983; 4:29-35.

25. Odeku OA, Itiola OA, Compaction Properties of Three Types of Starch, Iranian Journal of Pharmaceutical Research, 2007; 6(1):17-23

26. Fox CD, Richman MD, Reier GE, Shangraw RF, Drug Cosm. Ind., 1963, 92:161

27. Huttenrauch R, Shangraw RF, J. Pharm. Sci., 1966; 55:510 